\title{
Stimulation of the Growth of Cutaneous Strains of Peptococcus saccharolyticus by Iron, Haematin and Blood
}

\author{
By MARK S. STROM, HOWARD C. DOUGLAS AND \\ CHARLES A. EVANS* \\ Department of Microbiology and Immunology, University of Washington, School of \\ Medicine, Seattle, Washington 98195, U.S.A.
}

(Received 16 February 1981; revised 10 June 1981)

\begin{abstract}
The growth of nine strains of Peptococcus saccharolyticus was assessed quantitatively by culture on Trypticase Soy/yeast extract/Tween 80 agar (TSY-TW) with and without supplementation with iron or haematin and on blood agar, in aerobic, reduced $\mathrm{O}_{2}\left(3 \% \mathrm{O}_{2}\right.$ with $8 \% \mathrm{CO}_{2}, 8 \% \mathrm{H}_{2}$ and $81 \% \mathrm{~N}_{2}$ ) and anaerobic atmospheres. All strains grew better anaerobically and under reduced $\mathrm{O}_{2}$ conditions than aerobically on supplemented or unsupplemented TSY-TW. Supplementation of TSY-TW with iron or haematin resulted in an average 4.4-fold increase in bacterial count in a reduced $\mathrm{O}_{2}$ atmosphere and an average 4-2-fold increase under anaerobic conditions. Under aerobic conditions the increase in count ranged from 0 to $>5000$-fold, as some strains failed to grow on unsupplemented TSY-TW but responded well to the supplements of iron or haematin. The highest bacterial counts were obtained on Columbia blood agar incubated anaerobically. However, P. saccharolyticus failed to grow aerobically on plain or heated Columbia blood agar with or without supplements. TSY-TW blood agar supported the growth of the one strain tested under all three atmospheric conditions. The type strain (ATCC 14953) differed from all others in its failure to grow aerobically or in a reduced $\mathrm{O}_{2}$ atmosphere on supplemented or unsupplemented media. Colony size varied greatly on different media, in different atmospheres and from strain to strain, being greatest in a reduced $\mathrm{O}_{2}$ atmosphere on Columbia blood agar. There was no correlation between the viable bacterial count and colony size.
\end{abstract}

\section{INTRODUCTION}

Previous publications from this laboratory (Evans \& Mattern, 1978; Evans et al., 1978) reported that Peptococcus saccharolyticus was a numerically important member of the flora of the forehead of $20 \%$ of subjects and that a similar proportion of individuals carried the organism on the antecubital fossa of their arms. Strains chosen as representative of different sources and different times of isolation had an exceptionally high degree of relatedness judged by metabolic activities and DNA homology (Crosa et al., 1979; Kilpper et al., 1980). Peptococcus saccharolyticus produced larger colonies on Columbia blood agar in an atmosphere of $4 \%(\mathrm{v} / \mathrm{v}) \mathrm{O}_{2}$ with added $\mathrm{H}_{2}$ and $\mathrm{CO}_{2}$ than on the same medium or other media in anaerobic conditions. Here we report that the addition of iron or haematin to Trypticase Soy/yeast extract/Tween 80 agar (TSY-TW) did not increase colony size on this medium but did result in an increase in the bacterial count not only under anaerobic conditions but also aerobically and in the presence of reduced $(3 \%, \mathrm{v} / \mathrm{v}) \mathrm{O}_{2}$.

\section{METHODS}

Media. The standard medium (TSY-TW) contained 3\% (w/v) Trypticase Soy Broth (BBL), $1 \%(w / v)$ yeast extract (Difco) and $0.1 \%(\mathrm{v} / \mathrm{v})$ Tween 80 (polyoxyethylene sorbitan mono-oleate; Sigma); the final pH was 7.0. 
Supplemented media contained added haematin or iron. Haematin (Sigma, from bovine blood) was prepared as a $7.9 \mathrm{~mm}$ solution in $0.2 \mathrm{M}-\mathrm{KOH}$ and filter-sterilized with $0.45 \mu \mathrm{m}$ membrane filters (Ritchey \& Seeley, 1976). This solution was added to TSY-TW at $45-50{ }^{\circ} \mathrm{C}$ just prior to pouring to give final haematin concentrations of 0.016 , $0.032,0.048$ and $0.080 \mathrm{~mm}$ as required. Ferrous iron was added as a filter-sterilized $36 \mathrm{~mm}$ solution of $\mathrm{FeSO}_{4}$ (J. T. Baker Chemical Co.) in distilled water to give final concentrations of $0.0036,0.036,0.36,1.8$ and $3.6 \mathrm{~mm}$ as required. The addition of haematin or iron to TSY-TW had no appreciable effect on the $\mathrm{pH}$ of the medium either before or after incubation in the atmospheres used. In a few experiments, other compounds were added to TSY-TW: $0.034 \mathrm{~mm}$-protoporphyrin IX dimethylester (Sigma; dissolved in acetone prior to addition to TSY-TW). $0.24 \mathrm{mM}_{-} \mathrm{Fe}_{2}\left(\mathrm{SO}_{4}\right)_{3}, 0.36 \mathrm{~mm}-\mathrm{FeCl}_{2}$ and $0.36 \mathrm{~mm}-\mathrm{MgSO}_{4}$.

Columbia agar base (BBL) and defibrinated sheep blood $(5 \%, v / v)$ were used to make blood agar. In some comparative tests haematin or $\mathrm{FeSO}_{4}$ was added to the Columbia blood agar to give the same concentration as that in the supplemented TSY-TW.

Media were prepared in $100 \mathrm{~mm}$ Petri dishes containing two compartments (Falcon).

Bacterial strains. The nine strains of Peptococcus saccharolyticus used were strains that had been included in the study of DNA homology and physiological characteristics (Crosa et al., 1979). They were isolated from the normal skin of seven subjects who were students or members of the faculty or staff of the Department of Microbiology and Immunology, University of Washington. Stock cultures used in the experiments described below were prepared by first cultivating the bacteria anaerobically on TSY-TW using the BBL GasPak Anaerobic System. Fresh cultures of each strain were suspended in a freezing medium consisting of equal parts of $\gamma$-globulin-free newborn calf serum (Grand Island Biological Co.) and TSY broth and were kept frozen in $1.0 \mathrm{ml}$ portions in glass vials at $-20{ }^{\circ} \mathrm{C}$ until required.

Growth comparisons. Frozen stock cultures of known bacterial count were rapidly thawed and serial 10 -fold dilutions were prepared in $37.5 \mathrm{~mm}$-phosphate buffer, $\mathrm{pH} 7 \cdot 9$, containing $0.05 \%(\mathrm{v} / \mathrm{v})$ Triton X-100 (New England Nuclear). Three plates of each medium were inoculated by spreading $0.05 \mathrm{ml}$ portions of an appropriate dilution of a culture on the surface of both compartments of each plate. Sterile bent glass rod spreaders were not used on more than one type of medium in order to prevent possible transfer of growth factors. One set of plates was incubated aerobically. The other two sets were placed in separate vented anaerobe jars (BBL) from which air was evacuated and replaced with either a gas mixture with a reduced $\mathrm{O}_{2}$ concentration $\left(\mathrm{O}_{2} / \mathrm{H}_{2} / \mathrm{CO}_{2} / \mathrm{N}_{2}\right.$, $3: 8: 8: 81, \mathrm{v} / \mathrm{v}$; Matheson Gas Products) or a mixture lacking $\mathrm{O}_{2}\left(\mathrm{H}_{2} / \mathrm{CO}_{2} / \mathrm{N}_{2}, 8: 8: 81, \mathrm{v} / \mathrm{v}\right.$; Airco Industrial Gases). Residual traces of $\mathrm{O}_{2}$ were removed from the jars with the anaerobic gas mixture by a cold palladium catalyst, and anaerobic conditions were monitored with disposable oxygen indicators (BBL).

Colony counts and median colony diameters were determined after incubation for $5-6 \mathrm{~d}$ at $35^{\circ} \mathrm{C}$. Each strain was tested at least twice on iron- and haematin-supplemented media and on Columbia blood agar.

\section{RESULTS AND DISCUSSION}

\section{Effect of various supplements}

From the results of preliminary tests with TSY-TW supplemented with haematin and $\mathrm{FeSO}_{4}$ at various concentrations, it was concluded that $0.032 \mathrm{mM}$-haematin and $0.36 \mathrm{~mm}$ $\mathrm{FeSO}_{4}$ were close to the optimum concentrations in the three atmospheres, as judged by viable counts. Therefore, these concentrations were used in all subsequent experiments.

Tests with ferric iron $\left[0.24 \mathrm{mM}-\mathrm{Fe}_{2}\left(\mathrm{SO}_{4}\right)_{3}\right]$ and another form of ferrous iron $(0.36 \mathrm{~mm}$ $\mathrm{FeCl}_{2}$ ) gave results comparable to those with $\mathrm{FeSO}_{4}$. The addition of $0.36 \mathrm{mM}-\mathrm{MgSO}_{4}$ or $0.034 \mathrm{~mm}$-protoporphyrin IX to TSY-TW did not result in increased counts of $P$. saccharolyticus in tests with three strains.

Supplementing TSY-TW with iron or haematin resulted in increased viable counts in $86-100 \%$ of tests in the various combinations of media and atmospheres (Table 1). The type strain, ATCC 14953, differed from the others in that growth was stimulated under anaerobic conditions, but even large inocula did not grow aerobically or in reduced $(3 \%) \mathrm{O}_{2}$ on any of the supplemented media.

The responses to iron and haematin were similar under anaerobic and reduced $\mathrm{O}_{2}$ conditions. Two strains were exceptions in that iron was inhibitory or gave minimal stimulation anaerobically while haematin gave strong stimulation. Both strains responded well to iron and to haematin under aerobic and reduced $\mathrm{O}_{2}$ conditions. Some of the most striking effects were seen with aerobic culture of strains that gave 100-5000 colony-forming units (c.f.u.) on supplemented TSY-TW but failed to grow on unsupplemented media. 
Table 1. Increase in viable counts of $P$. saccharolyticus with addition of haematin or iron to TSY-TW

\begin{tabular}{|c|c|c|c|c|c|}
\hline \multirow{2}{*}{$\begin{array}{l}\text { Addition } \\
\text { to TSY-TW }\end{array}$} & \multirow{2}{*}{$\begin{array}{l}\text { Incubation } \\
\text { atmosphere }\end{array}$} & \multirow{2}{*}{$\begin{array}{l}\text { No. of } \\
\text { tests }\end{array}$} & \multirow{2}{*}{$\begin{array}{l}\text { Percentage of } \\
\text { tests showing } \\
\text { increase }\end{array}$} & \multirow{2}{*}{$\begin{array}{c}\text { Range of } \\
\text { increase in viable count } \\
\left(\log _{10} \text { c.f.u. }\right) \neq\end{array}$} & \multirow{2}{*}{$\begin{array}{c}\text { Average ratio: } \\
\text { Growth with supplement } \\
\text { Growth without supplement }\end{array}$} \\
\hline & & & & & \\
\hline $\begin{array}{l}\mathrm{FeSO}_{4} \\
\quad(0.36 \mathrm{~mm})\end{array}$ & $\begin{array}{l}\text { Aerobic } \\
3 \% \mathrm{O}_{2} \\
\text { Anaerobic }\end{array}$ & $\begin{array}{l}18^{*} \\
18^{*} \\
19^{+}\end{array}$ & $\begin{array}{r}100 \\
94 \\
95\end{array}$ & $\begin{array}{l}0.0->3.7 \\
0.0-1.4 \\
0.0-1.5\end{array}$ & $\begin{array}{l}-\$ \\
4 \cdot 6 \\
3 \cdot 6\end{array}$ \\
\hline $\begin{array}{l}\text { Haematin } \\
(0.032 \mathrm{~mm})\end{array}$ & $\begin{array}{l}\text { Aerobic } \\
3 \% \mathrm{O}_{2} \\
\text { Anaerobic }\end{array}$ & $\begin{array}{l}22^{*} \\
22^{*} \\
25\end{array}$ & $\begin{array}{r}86 \\
100 \\
96\end{array}$ & $\begin{array}{r}0.0->3.5 \\
0.1-1.9 \\
-0.1-1.9\end{array}$ & $\begin{array}{l}-\S \\
4 \cdot 2 \\
4 \cdot 7\end{array}$ \\
\hline
\end{tabular}

On rare occasions a strain that failed to respond to supplementation in one test showed typical stimulation in subsequent tests. At present these anomalies cannot be explained.

These tests indicate that iron, in either its ferric or ferrous form, is necessary for optimal initiation of growth of $P$. saccharolyticus, possibly as a requirement for synthesis of haem-containing cytochromes or other enzymes. This conclusion is supported by the fact that haematin is active as a growth factor while its precursor protoporphyrin IX, which lacks iron, is not. Since ferric iron was active, the iron did not function simply as a reducing agent in the medium.

To give approximately the same level of stimulation, the molar concentration of iron required was about 10 -fold greater than the concentration of haematin. This difference could be due to external factors, such as the presence of iron-binding compounds that reduced the amount of available free iron in the medium, or the formation of insoluble iron oxides. Alternatively, cellular factors such as different uptake systems for haematin and iron could be responsible with an iron-binding siderochrome being the limiting factor.

\section{Viable counts on media containing blood}

In tests performed under anaerobic or reduced $\mathrm{O}_{2}$ conditions, the viable counts on blood agar prepared with Columbia agar base generally equalled or exceeded the counts on TSY-TW supplemented with iron or haematin. One strain was exceptional, yielding on blood agar only $0-25 \%$ of the viable count obtained on TSY-TW. Under aerobic conditions with large inocula (suspensions that gave $10^{5}-10^{7}$ c.f.u. under anaerobic conditions) all strains showed either no growth, a delicate film of growth, or tiny colonies $(<0.05 \mathrm{~mm} \mathrm{diam}$.). There was no improvement in aerobic growth on Columbia blood agar following the addition of haematin, iron or $0.5 \%(\mathrm{w} / \mathrm{v})$ glucose. Addition of glucose and iron to Columbia blood agar had no effect on growth under anaerobic or reduced $\mathrm{O}_{2}$ conditions, but the addition of haematin decreased the yield of viable organisms (three tests with one strain). Columbia blood agar heated to $80^{\circ} \mathrm{C}$ for $15 \mathrm{~min}$ also failed to support aerobic growth in tests with four strains. On this medium, the viable count was also decreased under reduced $\mathrm{O}_{2}$ and anaerobic conditions. However, in two of three tests, the type strain (ATCC 14953), which failed to grow in reduced $\mathrm{O}_{2}$ on TSY-TW with added haematin or iron, did so on heated blood agar, although the yields were only $0.5 \%$ and $10 \%$ of that obtained under anaerobic conditions.

One strain which grew poorly under aerobic conditions on Columbia blood agar was inoculated on to TSY-TW blood agar. Viable counts on this medium under anaerobic and reduced $\mathrm{O}_{2}$ conditions were equal to or greater than the counts for anaerobic growth on 
Columbia blood agar. Notably, this strain also grew well aerobically on TSY-TW blood agar, giving counts ranging from $60-100 \%$ of that for anaerobic growth on Columbia blood agar. This could be accounted for by the fact that red blood cells lyse in a few days when added to TSY-TW, perhaps as a result of the action of Tween 80 on cell membranes, thereby freeing haem or haemoglobin for use by the bacteria.

The lack of growth in air on heated or unheated Columbia blood agar, with or without supplementation, is surprising and suggests the absence of some growth factor which is necessary for aerobic growth or the presence of an inhibitor active only in an $\mathrm{O}_{2}$-containing atmosphere.

\section{Size of colonies}

As found previously (Crosa et al., 1979), the colony diameter of $P$. saccharolyticus was greatest when the bacteria were grown on Columbia blood agar under reduced $\mathrm{O}_{2}$ conditions. Compared with anaerobic conditions, colonies obtained under reduced $\mathrm{O}_{2}$ conditions were 1.2-6.5 times larger in diameter. Two exceptions were the type strain (ATCC 14953), which failed to grow in the presence of reduced $\mathrm{O}_{2}$ on blood agar, and one other strain, which exhibited poor growth on blood agar. In general, under anaerobic and reduced $\mathrm{O}_{2}$ conditions, colonies were smaller on TSY-TW supplemented with iron or haematin than on unsupplemented TSY-TW. Under aerobic conditions, colonies on iron-supplemented TSY-TW were usually the same size as those on unsupplemented TSY-TW, but addition of haematin produced somewhat larger colonies.

There was, however, considerable variation between strains with respect to colony size on various media and different atmospheres. Bacterial counts did not correlate well with colony size. For example, a few strains that gave high counts on iron-supplemented TSY-TW when incubated anaerobically produced colonies that were 6-8 times smaller in diameter than when grown on unsupplemented TSY-TW. One of the strains that showed decreased counts under anaerobic conditions on iron-supplemented TSY-TW formed larger colonies than were seen on unsupplemented TSY-TW. More commonly, colonies were of the same size on supplemented and unsupplemented TSY-TW.

\section{The classification of $P$. saccharolyticus}

The effect of haematin and iron on the growth of $P$. saccharolyticus raises questions with respect to the cutaneous ecology of the organism, its taxonomic status and its nutrition and metabolism.

Variation in the concentration of available iron in the cutaneous microhabitat may account for the fact that only $20 \%$ of subjects harbour P. saccharolyticus (Evans \& Mattern, 1978; Evans et al., 1978). Sweat collected by thermal induction or after exercise has been reported to contain 0.1-3.8 $\mu \mathrm{g}$ iron $\mathrm{ml}^{-1}$ (Seutter \& Sutorius, 1972; Cohn \& Emmett, 1978). Normal evaporation could be expected to raise this level substantially. Since $P$. saccharolyticus occurs in a 'sheltered' condition, as indicated by resistance to alcohol disinfection (Evans \& Mattern, 1980 ), it probably colonizes the pilosebaceous units, a site where the availability of iron is apparently unknown.

The classification of $P$. saccharolyticus as a member of the genus Peptococcus has been challenged on the basis of its fermentative capabilities, the chemical constituents of its cell wall and nucleic acid homology studies (Schleifer \& Nimmerman, 1973; Rogosa, 1974; Kilpper et al., 1980). Its status as an anaerobe is also questionable. The composition of the growth medium determines whether $P$. saccharolyticus conforms to the definition of an anaerobe as an organism that 'thrives best or only when deprived of oxygen' (Stedman's Medical Dictionary, 1966). On TSY-TW it meets this criterion but on supplemented media or blood agar it often does not, as equal growth (viable count) occurs anaerobically and in the presence of 3 or $4 \% \mathrm{O}_{2}$ with added $\mathrm{CO}_{2}$ (microaerophilic conditions). The term 'thrives best' also requires definition. In our tests plating efficiency did not correlate well with colony size 
and this kind of discrepancy between initiation of growth on various media and the amount of growth has been well known for many years (Miles \& Misra, 1938).

This study was supported by grant AM 22082 from the National Institutes of Health, Bethesda, Maryland, U.S.A.

\section{REFERENCES}

Cohn, J. R. \& Emmetr, E. A. (1978). The excretion of trace metals in human sweat. Annals of Clinical Laboratory Science 8, 270-275.

Crosa, J. H., Williams, B. L., Jorgensen, J. J. \& Evans, C. A. (1979). Comparative study of deoxyribonucleic acid homology and physiological characteristics of strains of Peptococcus saccharolyticus. International Journal of Systematic Bacteriology 29, 328-332.

Evans, C. A. \& Mattern, K. L. (1978). Individual differences in the bacterial flora of the skin of the forehead: Peptococcus saccharolyticus. Journal of Investigative Dermatology 71, 152-153.

Evans, C. A. \& MATTERn, K. L. (1980). The bacterial flora of the antecubital fossa: the efficacy of alcohol disinfection of this site, the palm and the forehead. Journal of Investigative Dermatology 75, 140-143.

Evans, C. A., Mattern, K. L. \& Hallam, S. L. (1978). Isolation and identification of Peptococcus saccharolyticus from human skin. Journal of Clinical Microbiology 7, 261-264.

Kilpper, R., Buhl, U. \& Schleifer, K. H. (1980). Nucleic acid homology studies between Peptococcus saccharolyticus and various anaerobic and facultative anaerobic gram-positive cocci. FEMS Microbiology Letters 8, 205-210.

Miles, A. A. \& MisRA, S. S. (1938). The estimation of the bactericidal power of the blood. Journal of Hygiene 38, 732-749.

Ritchey, T. W. \& Seeley, H. W. (1976). Distribution of cytochrome-like respiration in streptococci. Journal of General Microbiology 93, 195203.

Rogosa, M. (1974). Family III. Peptococcaceae. In Bergey's Manual of Determinative Bacteriology, pp. 517-522. Edited by R. E. Buchanan \& N. E. Gibbons. Baltimore: Williams \& Wilkins.

Schleifer, K. H. \& Nimmerman, E. (1973). Peptidoglycan types of strains of the genus Peptococcus. Archiv für Mikrobiologie 93, 245-258.

Seutter, E. \& Sutorius, A. H. M. (1972). The quantitative analysis of some constituents of crude sweat. II. Zinc, copper, iron, sialic acid content and oxidative activity. Dermatologica 145, 203-209.

STEDMaN's MEdical DictionaRY (1966). 21 st edn, p. 74. Baltimore: Williams \& Wilkins. 